\title{
The Impact of the Fourth Industrial Revolution on Organizational Control
}

\author{
Orly Yeheskel \\ Coller School of Management, Tel Aviv University, Israel \\ Shlomo Globerson \\ Coller School of Management, Tel Aviv University, Israel
}

Received: Sep. 22, 2020 Accepted: Oct. 27, 2020 Online published: Nov. 18, 2020

doi:10.5296/ijhrs.v10i4.17954ＵRL: https://doi.org/10.5296/ijhrs.v10i4.17954

\begin{abstract}
The disruption and chaos experienced by businesses and other organizations during the fourth industrial revolution, which have intensified during the Corona epidemic, are creating major managerial challenges for executives and organizations, forcing them to operate in a volatile, uncertain. Such a situation requires a more sophisticated approach that includes swift and flexible managerial and response mechanisms, alongside mechanisms based on continuity and order, and the appropriate modifications to the managerial and organizational systems.

The article presents perspectives and insights related to the question of how chaos, disruption and change are affecting managerial approaches in general and managerial control in particular.

The traditional control systems were developed to manage continuous processes rather than the sudden and volatile events that characterize a chaotic environment. Sudden or unexpected events are in fact similar with respect to their control needs to project management since they have a defined starting point that requires a specific response, one that is not always possible to predict. Therefore, we suggest that traditional control be combined with project control. This will create a control infrastructure that combines order and chaos.
\end{abstract}

Keywords: management control, fourth industrial revolution, change management, VUCA, chaotic organization 


\section{Introduction}

\subsection{The Industrial Revolutions}

Since the scientific management movement sparked during the second industrial revolution by Taylor in 1911, the notion "you cannot manage what you do not measure", has been adopted by most managers. This was essential since no manager is able to be actively involved in every single operation and know the relevant details necessary to support his decisions. Therefore, a proper measurement and control system, viewed as the eyes of the manager, is needed.

The second industrial revolution, which can be seen as having taken place during the period of 1870 to 1914 , was oriented towards capital-intensive factories, and productivity increase via technological improvement. Major innovations were related to the improvement of communication and transport.

The third industrial revolution (Kohnová \& Salajová, 2019) may be considered as the one started during the second half of the 20th century, with the emergence of the transistor and the microprocessor. It resulted in the development of telecommunications and computers, and enabled the introduction of automation in both manufacturing and the service industries. Additional tools aimed at the analysis of man-machine systems were introduced. From the managerial point of view concerning the ability to control organizational operations, it had a strong impact on the way data was collected. Prior to this revolution, data was mostly collected manually, whereas from then on a significant portion of data needed to support managerial decisions was captured as part of the operations. But still, most of the organizations in that era worked in a relatively orderly and stable mode.

The fourth industrial revolution (FIR), presently underway, is based on the digital revolution with all its derivatives such the internet, big data, algorithms that describe the nature of phenomena, and the cloud. Digitalization enables the construction of a new virtual world, from which we can steer the physical world. It totally changes the processes, analysis, and management of the service and manufacturing industries all over the world.

\subsection{The Fourth Industrial Revolution}

Another significant change introduced by the FIR is in the labor market, which is moving aggressively in the direction of "cloud workers", using more freelancers and temporary workers who will often be working for several organizations simultaneously. This trend also increases significantly the proportion of subcontractors, who, by their nature, do not directly report to the organization to which they are contracted.

The pace and intensity of the changes during the FIR differ from anything we have seen in the past. It sometimes appears that the world order is changing; it is a kind of chaos with boundaries, intensity and trajectory that cannot be explained or even imagined. Technological, demographic, sociological and cultural change is taking place worldwide and is being accompanied by global political, geopolitical and macroeconomic disruption. Accelerated globalization, alongside technological innovation, is facilitating an unprecedented flow of 
goods, services, knowledge, information, people, capital (and even viruses) across local borders, and is exposing organizations to formidable managerial challenges. In the business world, boundaries are disappearing and new competitors are emerging from various directions in the traditional industries, which are finding themselves in a process of disruption.

How will this chaos, disruption, change and innovation affect the managerial approaches in general, and management control in particular? These questions form the core of this article, in which we will present some thoughts and perspectives to support managers in their decision making.

\subsection{Environmental Challenges}

The environmental challenges faced by organizations throughout all the revolutions, with an increasing intensity over time, can be summarized by the following dimensions, namely volatility, uncertainty, complexity and ambiguity. Together they are referred to as VUCA.

Volatility - extreme fluctuations of intensity and frequency that is difficult to predict (Sullivan, 2012; Lawrence, 2013).

Uncertainty - a lack of ability to predict events or to predict the implications of events whose occurrence may be predictable but not their effects (Bennett \& Lemoine, 2014).

Complexity - the ability to complete missions becomes more difficult due to globalization of both production processes and customers (Bennett \& Lemoine, 2014), the specialization that requires more parties to be involved in the process, and the extensive use of subcontractors that are not under the organizational umbrella.

Ambiguity - information and its effects can be understood in more than one way. The opacity with respect to the logic or the rules that underlie existing information creates confusion (Lawrence, 2013) and undermines the ability to make correct decisions. For example, the data on the spread of the Corona virus, exists; however, there are various ways to convert it to information, each leading to a different interpretation concerning its spread and its implications - a situation that is liable to create confusion with regard to the proper way to handle the virus.

The VUCA concept is an old one that was coined in US military academia after the Cold War to characterize the changes and challenges which the American military must be prepared to confront in the $21^{\text {st }}$ century (Kinsinger and Walch, 2012). The main emphasis of the concept in the military context is on the transition from clear and well-structured doctrines that are based on prediction and planning and known enemies, to a world that includes a high level of complexity; "asymmetric" enemies and truths that are contradictory and complex and which require rapid and diverse responses; an ability to adapt; and decision making in situations of ambiguity and uncertainty (Schoemaker, Heaton \& Teece, 2018).

Over the years, the VUCA concept has been widely adopted in the business world as a way to describe a world of volatility and turbulence. The era of stability has come to an end. Thus, business organizations must make quantum shifts in decision making, organizational structure, 
the management of innovation and the achievement of competitive advantages. Organizations in traditional industries, such as banking, retail, insurance, real estate, media, medicine and even education, are undergoing disruptive processes in response to competing business models and a changing regulatory environment. They are fighting to retain their customers and their suppliers and must develop agility, innovation, new approaches to HR management and structural models and managerial processes that depart from the classic paradigms (Lawrence, 2013).

The above interaction among the four VUCA components creates a complex and risky decision-making environment (Sullivan, 2012) in which managers need a proper set of tools That is, the traditional set of tools should be adapted to fit the new VUCA environment.

The rate of change in an organization's environment is greater than the speed with which the classic managerial structures and processes can cope, even if various modifications are made. A move must be made in the direction of agile control structures and processes, which will provide the organization with a degree of flexibility and ability to adapt quickly, which is needed in order to deal with the growing volatility in the environment. The concept of agility originates from the software world. Doz and Kosonen (2008) define agility as the ability of an organization to change and adapt in a continuous and dynamic way in response to changes in the market. The agility approach has expanded very rapidly and became the leading principle in the thinking about and design of modern organizations. The achievement of agility requires a trend away from serial, rigidly controlled, long-lived and final-goal-oriented processes, towards parallel and short-lived processes that facilitate learning and correction at each of their stages.

The FIR set of tools should include both a structured and an unstructured support system. The structured system deals with orderly operations, typically consisting of ongoing production of products of similar nature, where relatively formulated support tools are used. The unstructured one deals with operational environment that require providing flexibility, agility, innovation, creativity, and imagination.

Dealing with a turbulent and complex world involves combining the two systems in order to deal with chaordic organizations blending characteristics of chaos and order that possess precise control systems, along with flexibility, learning capability, innovation, diversity, freedom from internal conflicts and high levels of self-management (Mitleton-Kelly, 2003). The chaordic approach is designed to create movement and renewal alongside organizational resilience that enables change and transformation in a way that will not undermine the organization and threaten its continuing existence.

\section{The Required Control Systems}

As FIR era organizations have to function in an environment in which both order and chaos live side by side, they need tools to tackle both, as presented below.

The two different control systems that are required have common components as well as unique ones. The first will be referred as the orderly one, and the second as the flexible one. The orderly control system is based on the traditional one, but revised to fit the new 
environment of orderly operations. The flexible control system is based on the principles of project management control but adjusted to fit other environments as well.

\subsection{The Orderly Control System}

A classical organizational orderly control system is based on the use of a selected set of performance criteria to be used for evaluating organizational performance, the comparison of actual performance on those criteria to benchmarks, and the initiation of changes to eliminate undesired discrepancies.

In today's business environment it is common for an organization wishing to compete for a contract to be required to show that it maintains a compatible control system (Epstein, Verbeeten \& Widener, 2018). A typical orderly control system is used to evaluate processes which deliver an end product, be it a manufacturing or a service one. Furthermore, the importance of a control system can be traced in different maturity models. International standards specify the organizational control features which a proper system should have; for example, ISO 10012:2003 specifies generic requirements and provides guidance for the management of measurement processes. An orderly organizational control system consists of the following components:

Performance criteria: measures used to evaluate end results of activities which are of importance for organizational success. The criteria selected by an organization for monitoring organizational progress are derived from those areas in which an organization wishes to improve its performance. Examples of such criteria are number of items sold per day, customers served per hour, labor hours per unit, cost per unit, response time to customer inquiry, tons of water per month, machine uptime, dollar output per dollar input, and so on. Some of the performance criteria can be further subdivided to obtain greater insight into the contributing variables. For example, when dealing with a criterion such as profitability, lower level performance criteria may be examined, such as expenses and revenues, which in turn have their own lower levels - cost per item and selling price per item, respectively. In other words, one can identify and use a hierarchy of performance criteria where one leads to the other or is derived from the other.

Performance criteria can be either objective or subjective. The measurement results of an objective criterion are supposed to be the same, regardless of the person responsible for the measurement. Obviously if the measurement is planned and built as part of an automated process, then its results will be objective. If the actual intensity of a criterion is assessed by an individual, it is obviously a subjective measure. For example, the quality of customer service is determined by the customer and is therefore an objective measure.

Even accepting that "you cannot manage what you do not measure", there are still quite a few features that are not so measurable, such as the proper handling of the decision-making process in recruiting new employees. In this case the function of control may be twofold: evaluating the existing formal process, and/or evaluating to what extent the actual process follows the one established.

Actual performance: the value of a performance criterion during a specific time period, 
expressed by the relevant unit of measurement. For example, during the last week of April an average of 0.50 labor hours were needed to completed a hospital insurance claim (AP $=0.50$ hrs/claim). Performance of important activities is monitored continuously in order to detect deviations and initiate corrective actions. However, there are also cases where a single measure is required to evaluate a specific situation and no continuous monitoring is needed.

Standard: a satisfactory level of actual performance which has to be determined by management, for each performance criterion. A standard is sometimes also referred to as the "norm". The value of a standard can be based either on the past performance of the organization, or on a "benchmark", namely the performance of other organizations that deal with work of the same nature. Continuing the previous example, let us assume that the standard established by the insurance company that handles hospital claims is STD $=0.45$ hrs/claim.

A standard can and should be revised periodically, since processes are improved continuously with an end result that fewer resources are needed to generate the same throughput. This phenomenon is commonly depicted by a learning curve.

Performance deviation: the difference between the standard and actual performance. Continuing the previous example, assuming that the standard established by the insurance company that handles hospital claims is $0.45 \mathrm{hrs} / \mathrm{claim}$, the average amount of labor hours spent on a claim exceeded the standard by $0.50-0.45=0.05 \mathrm{hrs} / \mathrm{claim}$.

Performance analysis: management's evaluation of the situation concerning the deviations, and possible reasons for them. In the above example, an analysis of the situation brought to the attention of management that last week was the first time that claims were submitted by a new contract that were different from the others processed by the company. However, it was not clear if and by how much the new claims differed significantly, or if the difference was just due to the learning curve phenomenon.

Intervention: analysis of deviation is typically carried out at the managerial level that is able to evaluate the situation and decide about the changes that should be introduced in order to properly deal with the undesired performance. Some organizations have periodical review boards that are responsible for monitoring organizational performance over time and for initiating corrective actions. Continuing the previous example concerning claim processing, as a result of the analysis, the following decisions were made: to monitor the production of the new contract separately, as expressed by the count and by the labor hours used for it.

An important feature in a control system is its measurement cycle, that is, how often performance criteria are measured. Although more and more criteria are measured continuously as part of the process, there are still others that have to be measured independently. Figure 1 presents the relationship between the measurement cycle and the potential ensuing damage as a function of the response delay.

The following are the meanings of the notations used in Figure 1:

$\mathrm{A}$ - the time when an undesired value was detected. 


\section{Macrothink \\ International Journal of Human Resource Studies

B - damage intensity when the undesired value was detected

$\mathrm{RT}$ - Response Time - time taken from detection to the correcting response.

$\mathrm{C}-$ the time when response to the malfunction was initiated: $\mathrm{C}=\mathrm{A}+\mathrm{RT}$.

D - total damage generated until corrective action was taken.

\section{Damage}

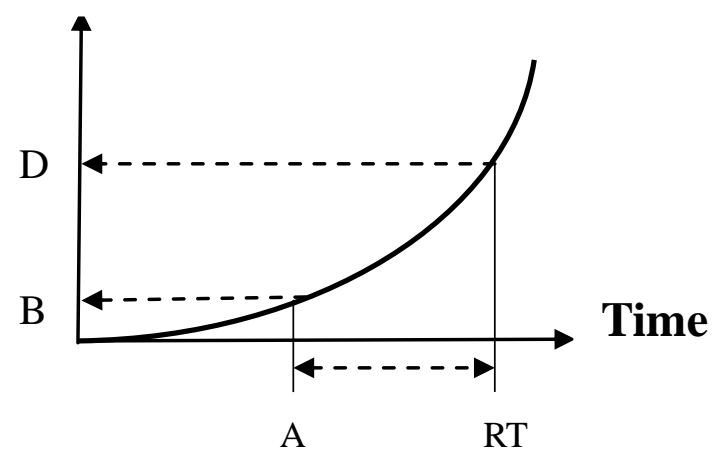

Figure 1. Damage intensity as a function of its detection time and the time required to initiate corrective action

A typical damage function grows exponentially, as presented in Figure 1. Therefore, it is of the utmost importance to detect it as early as possible

The relationships among the control process components are represented by the control loop in Figure 2. Based on organizational strategy and objectives, performance criteria and are selected, and production processes are established. Actual performance measures are monitored and standard setting takes place. Performance analysis is then implemented, with emphasis on the difference between actual performance on each relevant criterion and the standard. As a result of the analysis, intervention takes place, by making decisions aimed at initiating actions to close undesired gaps, or generating further performance improvements. These decisions typically deal with resource allocation, technological changes of both the product/service and the process, and scheduling. 


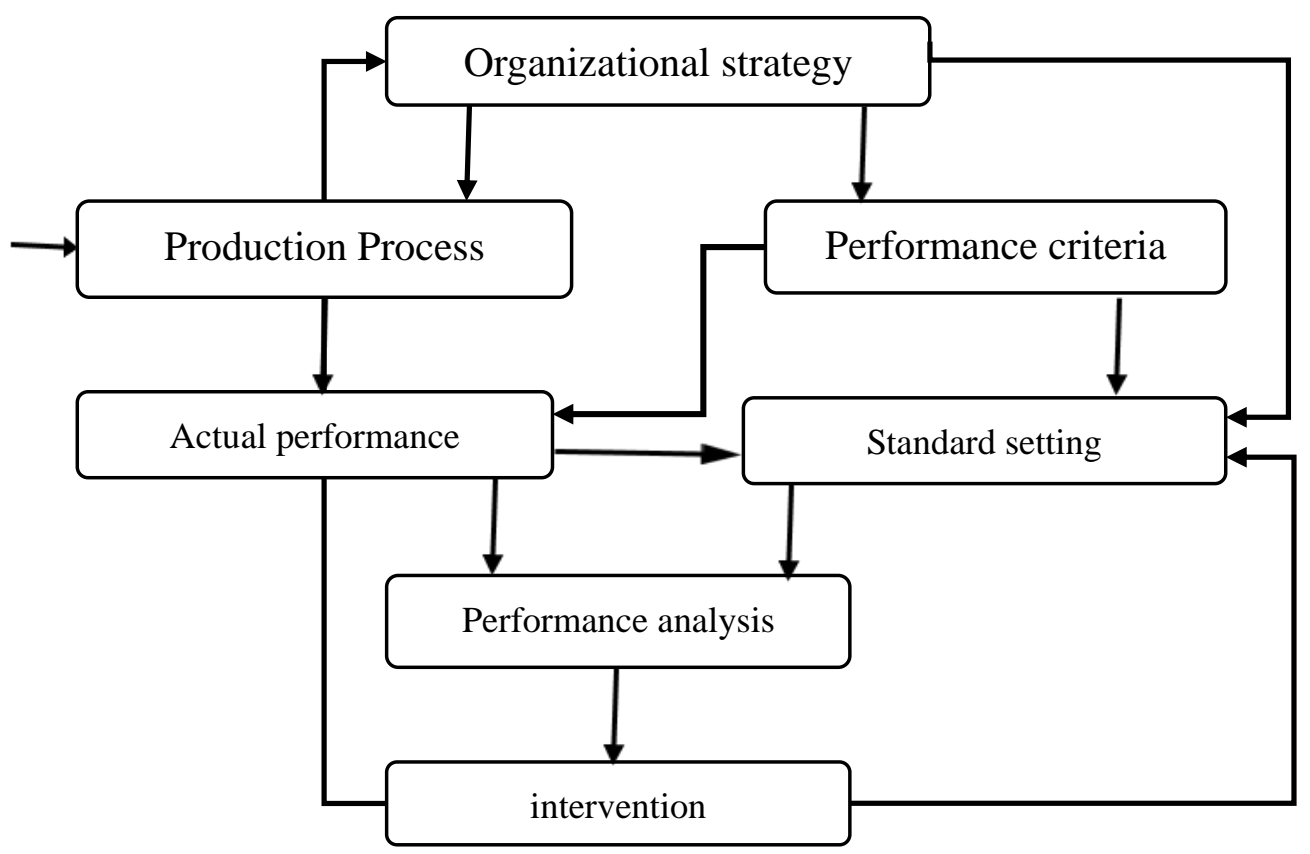

Figure 2. The control loop

This process stops only when an organization ceases to exist.

The management control system in every organization is dynamic in nature as it needs to conform to organizational strategy and the environment in which the organization functions. That is, organizational control needs to be changed according to the changes introduced into the organizational strategy. For example, if an organization decides to concentrate on quality upgrade, then the organizational control system should be adjusted to emphasize quality-related performance criteria.

Similarly, if there are significant environmental changes, then the control system should be adjusted to them as well. For example, the increased information transfer ability afforded by the FIR has led to increased government agency demands for various performance-related reports that are oriented towards service level provided to customers. Therefore, organization control needs to make all the required changes to respond to this request.

The next paragraph reviews the impact of the FIR on the traditional orderly organizational control system.

Not all of the many facets of the FIR have an impact on the traditional orderly control system. The following is a list of those which do have an impact.

- Increased introduction of technology in all processes

- Intensifying automation

- Automation of measurements

- Reduction of human involvement

- Introduction of automated data collection mechanisms in all processes

- Continuous data analysis 
- Automatic alerts for undesired discrepancies

- Self-corrections

- Use of algorithms for analysis

A summary of the impact of the FIR on the control loop components presented in Figure 2 appears in Table 1.

Table 1. Impact of the FIR on the control loop components

\begin{tabular}{|l|l|}
\hline \multicolumn{1}{|c|}{ The component } & \multicolumn{1}{c|}{ Impact of the FIR } \\
\hline Organizational strategy & Frequent changes \\
\hline Production process & Fewer people, built in data collection \\
\hline Performance criteria & Same as before \\
\hline Actual performance & Built into the process \\
\hline Standard setting & Same as before \\
\hline Performance analysis & Same as before, built into the process \\
\hline Intervention & Same as before, built into the process \\
\hline
\end{tabular}

The FIR does not affect the way that all of the orderly control components are treated. Some, such as establishing performance criteria, are done the same as before. That is, management selects the performance criteria that are best fitted to organizational strategy. There are other components, such as performance analysis, that are done both ways: sometimes it is the same as before and sometimes the data collection and analysis are built into the process.

\subsection{The Chaos Organizational Control System}

In the VUCA environment in which we presently live the notion of chaos represents the inability to predict what is coming and what is needed in order to properly prepare for the future. In other words, it is a state of disorder in which new needs suddenly appear as previous needs disappear. A new need may be the need to execute a project that has not been carried out before. In order for management to be able to properly respond to chaos situations they need to be equipped with the appropriate tools and techniques. The chaos tool box is dynamic in nature and differs from the one used for an orderly situation. Since the future is unknown and therefore the responses to events are not known either, the tool box should be mostly based on general processes that can tackle strategic and operational problems that are different in nature.

An organizational strategy typically calls for changes required to move the company from one position to another. It is impossible to do this without initiating changes, with the changes being implemented via projects, both small and large. In other words, an organization expects to implement its strategy by a collection of selected projects that constitute the project portfolio. It is the assortment of projects executed by an organization that enables it to achieve the changes required to advance it from its current state to the prospective desired state.

The main body of knowledge upon which the chaos organizational tool box may be based is project management. In spite of the differences in the nature of different projects, a project 
management standard, called the Project Management Body of Knowledge - PMBOK, was developed by the Project Management Institute (PMBOK, 2017) and is being used all around the world. This standard specifies the generic processes that should be carried out in every single project and the essential ingredients for a process to be successful. It is oriented around the life cycle of a project as well as the required knowledge areas, as presented in Table 2.

Table 2. Number of processes to be properly executed, in every life cycle stage, in each knowledge area

\begin{tabular}{|l|l|l|l|l|l|}
\hline \multirow{2}{*}{ Knowledge area } & \multicolumn{5}{|c|}{ Life cycle stage } \\
\cline { 2 - 6 } & Initiation & Planning & Execution & Control & Closure \\
\hline Integration & 1 & 1 & 2 & 2 & 1 \\
\hline Scope & & 4 & & 2 & \\
\hline Schedule & & 5 & & 1 & \\
\hline Cost & & 3 & & 1 & \\
\hline Quality & & 1 & 1 & 1 & \\
\hline Resource & & 2 & 3 & 1 & \\
\hline Communication & & 1 & 1 & 1 & \\
\hline Risk & & 5 & 1 & 1 & \\
\hline Procurement & & 1 & 1 & 1 & \\
\hline Stakeholder & 1 & 1 & 1 & 1 & \\
\hline
\end{tabular}

Altogether there are 49 processes that are executed during the life cycle of a project, of which 12 processes belong to project control. For the project to be successfully completed, each of the processes should be properly accomplished. Each process consists of inputs, tools and techniques, and outputs which should be properly performed in order to successfully complete project. Let us demonstrate the specific structure of one of the processes in the area of control.

There are two control processes which are used to verify proper project scope, namely "control scope" and "validate scope". "Control scope" is carried out internally by the project management team, whereas "validate scope" is carried out externally by the client. The following is the specific structure of the process "validate scope".

The inputs to this process are project management plan, project documents, verified deliverables and work performance date. The tools and techniques used to execute the verification process are inspection methods and decision making. The outputs include work performance information, accepted deliverables, change request and project document updates.

Since a chaotic environment is characterized by frequent changes of needs, the projects generated are similar to innovation projects - new projects which have not been done before, with a lot of uncertainty during their development. Regardless of whether the project is an orderly one or a new one, all the 49 processes need to be accomplished. To contend with the uncertainty of the chaotic environment, the Scrum methodology emerged from the software 
world, and is increasingly being used in organizations to implement projects of various types (Hoda, Noble, \& Marshall, 2012). It is a methodology that divides the project into short stages ("sprints") and assigns each part of the project to workgroups and managers. At the end of each workday, short group ceremonies ("dailies") are held for the purpose of reporting, monitoring of progress and interactive exchange of information over the course of the process. The customer is exposed to parts of the product/project at various stages of the process for the purposes of learning and feedback. Working in a Scrum environment enables a faster response time for changes needed during the execution of a project. That is, the combination of the PMBOK and Scrum seem to be the appropriate response for managing in a chaotic environment; the processes included in the PMBOK standard are always present, but they are treated in a faster mode, to fit the nature of the project.

The organization also performs quite a few activities that are not related to projects. For example, it has to establish a human resource strategy concerning the use of subcontracting. Thus, it has to make sure that the decision-making process is properly handled, as the process dictates the result; a faulty process will probably lead to a bad decision, whereas a proper process will increase the probability of making the right decision.

The chaotic environment can also be typified as one that generates a flow of start-up projects that are expected to respond to new circumstances. Although they are projects, they are different in nature from conventional projects in the following dimensions.

- Their scope is dynamic, since information is continuously being obtained, with an immediate impact on the project's objective and therefore it scope.

- The organizational structure that deals with the project may be changed in response to changes in needs.

- At the end of each stage, there is an option to either continue to finance the project to the next stage, or end it before its completion.

- There is high uncertainty with regard to scope, type and amount of resources, time and budget.

- Investment sources are not clear.

- Documentation is verbal, rather than taking the form of drawings and quantities.

- The orientation is towards the product life cycle, whereas in conventional projects the orientation is towards the project life cycle.

- Time is the most crucial criterion!

\section{Conclusions}

The chaotic and turbulent nature of the current environment is forcing managers to adopt approaches and methodologies that provide agility and flexibility, in response to volatility and rapid change. At the same time, these conditions still requires the use of numerous mechanisms that create order and oversight, on a scale that facilitates the operation of the system. As a result, we are seeing the adoption of organizational structures, employment infrastructures, managerial processes and even organizational culture that include a chaordic solution on two parallel axes: the creation of order alongside flexibility, agility and innovation. This configuration creates non-linear organizations with more complex structures 
and processes are more complex.

That same combination of mechanisms that create order with mechanisms that create flexibility, a process we are observing in the general configuration of organizations, should also be integrated within an organization's control systems. In other words, the appropriate response to the challenges of a chaotic environment is a transition from "traditional order-controlled systems" to systems that combine an orderly approach with dynamic capabilities. In practice, this means a transition from control systems based on continuous, long-term and predictable processes to dynamic project-oriented control systems. The reason for adopting a project-oriented approach is the high level of volatility of the processes that need to be controlled and which no longer allow for a static approach. Such processes are similar in character to a project, with a defined starting point that calls for a rapid, appropriate and specific response, sometimes involving changes and modifications that are made on the go. Thus, the approach that is best-suited to the development of control systems under VUCA conditions is the combination of a classic project-oriented methodology (PMBOK), which will govern the orderly aspects of the process, with agile methodologies such as Scrum, which will foster the dynamic nature of the control process. This will facilitate dynamic interaction and on-the-go learning and modification throughout the process. Such an integration will advance the organization's control systems, as well its other managerial systems, along a chaordic trajectory, which is suited to the conflicting demands of the VUCA environment. In this way, it will improve the ability of managers to navigate the organizational ship in the storm that is engulfing it.

\section{References}

Bennett, N., \& Lemoine, J. (2014). What VUCA really means for you. Harvard Business Review, 92(1/2), 27.

Doz, Y., \& Kosonen, M. (2008). The dynamics of strategic agility: Nokia's rollercoaster experience. California Management Review, 50(3), 95-118. https://doi.org/10.2307/41166447

Epstein, M. J., Verbeeten, F. H. M., \& Widener, S. K. (Eds.) (2018).Performance Measurement and Management Control. Studies in Management and Financial Accounting, Vol. 33. Emerald. https://doi.org/10.1108/S1479-351220180000033001

Hoda, R., Noble, J., \& MARshall, S. (2012). Developing a grounded theory to explain the practices of self-organizing Agile teams. Empirical Software Engineering, 17(6), 609-639. https://doi.org/10.1007/s10664-011-9161-0

Kinsinger, P., \& Walch, K. (2012). Living and leading in a VUCA world. Thunderbird University, 542-555.

Kohnová, L., \& Salajová, N. (2019). Industrial revolutions and their impact on managerial practice: Learning from the past. Problems and Perspectives in Management, 17(2). https://doi.org/10.21511/ppm.17(2).2019.36

Lawrence, K. (2013). Developing leaders in a VUCA environment. UNC Exec Dev, 1-15. 


\section{Macrothink}

International Journal of Human Resource Studies

ISSN 2162-3058 2020, Vol. 10, No. 4

Mitleton-Kelly, E. (2003). Complex systems and evolutionary perspectives on organizations: the application of complexity theory to organizations. Elsevier Science Ltd.

P M B O K (2017). A Guide to the Project Management Body of Knowledge (pp. 2-111). Sixth Edition. Project Management Institute, Inc.

Schoemaker, P. J., Heaton, S., \& Teece, D. (2018). Innovation, dynamic capabilities, and leadership. California Management Review, 61(1), 15-42. https://doi.org/10.1177/0008125618790246

Sullivan, J. (2012). Talent strategies for a turbulent VUCA world-shifting to an adaptive approach, Ere. Retrieved from https://www.ere.net/talent-strategies-for-a-turbulent-vuca-world-shifting-to-an-adaptive-appr oach/

\section{Copyright Disclaimer}

Copyright for this article is retained by the author(s), with first publication rights granted to the journal.

This is an open-access article distributed under the terms and conditions of the Creative Commons Attribution license (http://creativecommons.org/licenses/by/4.0/). 